Literatura y Lingüística $\mathrm{N}^{\circ} 26$

ISSN 0716-5811/pp. 143-166

\title{
Apreciación de la fruta en obras literarias (I): entre poemas épicos y viajeros (siglos VIII- $\mathrm{XVI})^{*}$
}

\author{
Pablo Lacoste ${ }^{* *}$ \\ Amalia Castro ${ }^{* * *}$
}

\section{Resumen}

Este artículo indaga el proceso de reconstrucción de la cultura de apreciación de la fruta a través de la literatura entre el medioevo y el Renacimiento. En primer lugar, se examina la fruta en la temprana Edad Media, mediante el análisis de nueve obras de la literatura épica medieval. En ellas se refleja cómo, en la primera mitad de la Edad Media, Europa perdió la cultura de la fruta y los frutales que había desplegado durante la antigüedad. El segundo apartado examina el proceso de reconstrucción de la cultura de la apreciación de la fruta, a partir de la literatura musulmana: El Corán funcionó como disparador del proceso de recuperación de la cultura de los frutales, primero en Medio Oriente, y luego en las zonas de influencia de la expansión árabe. Finalmente, el tercer apartado examina relatos de viajeros, como los de Marco Polo y Nicolás de Nicolay, para verificar el asombro que la fruta causa a los ojos europeos.

Palabras clave: fruticultura, apreciación de la fruta, literatura épica medieval, Corán, viajeros, Marco Polo.

\section{Appreciation of fruit in literary works (I): between epic poems and travelers (From the $8^{\text {th }}-16^{\text {th }}$ century)}

\begin{abstract}
:
This article explores the process of rebuilding a culture of appreciation of the fruit through the literature from the Middle Ages and the Renaissance. First, we examine the fruit in the early Middle Ages, through the analysis of nine works of medieval epic literature. They reflect how, in the first half of the Middle Ages, Europe lost the culture of fruit that had developed during antiquity. The second section examines the process of rebuilding a culture of appreciation of the fruit from the Muslim literature, where the Koran worked as a trigger of the recovery process of the culture of fruit in the Middle East first, and then in the zones of influence of the Arab expansion. Finally, the third section, examines accounts of travelers such as Marco Polo and Nicolas de Nicolay, to see the amazement that fruit causes to European eyes.
\end{abstract}

Key words: fruit culture - fruit appreciation - medieval epic literature - Koran - travelers - Marco Polo.

Recibido: 10-10-2011 Aceptado: 05-05-2012

* Este artículo se enmarca en el Proyecto Fondecyt n 1080210, "Frutales y Sociedad en Chile: 1550-1930". Se agradece la colaboración de los ayudantes de este artículo: Matías Rojas, Max Concha, y Kissy Patiño.

** Doctor en historia. Académico Universidad de Santiago de Chile (USACH). Instituto IDEA. pablo.lacoste@usach.cl

*** Doctor @ en historia. Académico Universidad Católica Silva Henríquez. acastros@ucsh.cl 
Apreciación de la fruta en obras literarias (I): entre poemas épicos y viajeros (siglos VIII - XVI) / Pablo Lacoste, Amalia Castro

Más tarde o más temprano, el rey me considerará buen amigo. Sino, cuanto dijo no me importa un higo.

Cantar del Mio Cid

El proceso de introducción, expansión y estandarización de la producción y consumo de frutas en Europa, impulsado por las culturas clásicas de Grecia y Roma, en colaboración con otros pueblos antiguos como egipcios, fenicios y cartagineses, alcanzó su culminación en días del Imperio Romano. Pero, después de su derrumbe, al producirse el dislocamiento de las instituciones políticas, sociales y económicas, la situación cambió. Las condiciones dejaron de ser favorables para cuidar plantas que requerían muchos años para fructificar, mano de obra calificada para cultivarlas y elaborar sus frutos; la fragilidad del comercio medieval desalentaba productos de este tipo; la producción de frutas decayó en un contexto general de empobrecimiento de las condiciones de vida y de la dieta en particular.

Debido a ello, la presencia de la fruta en la Edad Media fue pobre. Las élites consumían carnes y pescados, mientras que el pueblo se alimentaba principalmente con cereales y legumbres. La figuración de las frutas quedaba reducida a algunas manzanas y peras, ocasionalmente, según algunos autores (Mennell, 1987). Otros coinciden con respecto al consumo de las pomáceas (Valdeón, 2004; Frossier, 2007) añadiendo algunas frutas más; el primero menciona ciruelas, cerezas y fresas (Valdeón, 2004: 94); el segundo coincide con el anterior en cuanto a la presencia de peras, manzanas, ciruelas y cerezas, a lo que suma: membrillos, higos, aceitunas, nueces y castañas; eventualmente, también podía hallarse algún cítrico (Frossier, 2007: 75). De todos modos, en este periodo, la fruta ocupaba un papel muy secundario en las prácticas alimentarias de Europa. Los huertos de castillos y monasterios cultivaban algunas plantas frutales, pero preferentemente orientadas a productos de valor simbólico como licores, tinturas y aceites (Páez, 1982).

Mientras Europa medieval perdía la cultura de las frutas, poco a poco, estas comenzaban a regresar al continente de la mano de los colonizadores musulmanes (árabes y bereberes). Desde el norte de África, estos se proyectaron hacia tierras del sur de Europa, tanto en Sicilia como en la península Ibérica. Allí, la renovación agrícola aportada por los musulmanes fue notable; incorporaron nuevas especies y variedades, juntamente con renovadas técnicas de cultivo y utilización de sus frutos. Establecieron eficaces sistemas de aprovechamiento del agua de ríos y

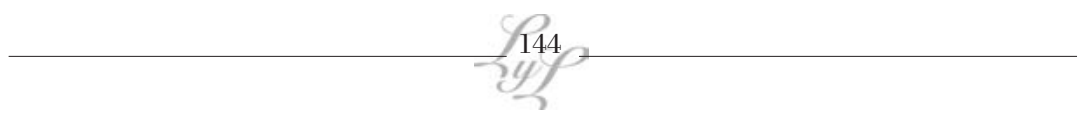


pozos; introdujeron la noria y construyeron canales de riego. Extendieron el cultivo de la vid, el olivo, la higuera y la morera, además de los cítricos, todo ello con un seductor entorno de jazmines y demás plantas aromáticas. El Calendario de Córdoba del año 961 reflejaba los notables avances en cultivo de viñas, olivares, higueras y limoneros (Valdeón, 2007: 32-33). Entre los siglos VIII y X se notaba una singular asimetría entre los reinos cristianos del norte, y los prósperos musulmanes del centro y sur de la península ibérica.

A diferencia de sus vecinos europeos, los árabes mantuvieron y enriquecieron el patrimonio cultural frutícola heredado de la antigüedad, patrimonio que extendieron con sus conquistas. Los musulmanes impulsaron el cultivo de diversas plantas frutales tanto en Sicilia como en la península ibérica. Ellos reintrodujeron frutales que se habían cultivado allí durante el imperio romano y, además, aportaron plantas nuevas, principalmente los cítricos (naranjo amargo, limonero, limo, cidro) presentes en el espacio hispano-árabe desde los siglos XII y XIII (Amorós, 2003: 23) e incorporaron la fruta no solo a la mesa de las elites, sino también a las capas populares. Sus avanzados conocimientos sobre fruticultura permitieron el incremento de la producción y el abastecimiento de los zocos, donde el pueblo acudía a comprar sus frutas en cantidades que hubieran asombrado a cualquier europeo del Medioevo (García Sánchez, 1995: 49-57). Los musulmanes generaron fuertes avances en fruticultura tanto desde el punto de vista botánico y agronómico como en el plano cultural. Ello se reflejó, por ejemplo, en los manuales de los agrónomos andalusíes (Carabaza Bravo, 2004).

Posteriormente, comenzó la recuperación de los cristianos, los cuales avanzaron hacia el sur, y absorbieron lentamente no solo las tierras, sino también la rica tradición agrícola musulmana, incluyendo su afianzada fruticultura (Valdeón Baruque, 2007: 53-62). Los nuevos reinos cristianos, emergidos de la reconquista, se apropiaron del empuje de los árabes en favor de las frutas (Pereira, 2010: 46). En el siglo XVII se destacaban las plantaciones de naranjos, limoneros y olivos en Portugal y España (Defourneaux, 1964: 14-15). Paralelamente, en la isla de Sicilia, ocurrió un proceso similar; la presencia árabe puso las bases para la futura expansión de la fruticultura, proceso que floreció en el marco del Renacimiento y alcanzó su punto culminante en el Barroco, particularmente en el palacio de Versalles. Cuando las potencias europeas iniciaron su expansión por el mundo, llevaron consigo este patrimonio biocultural. La fruticultura se proyectó hacia las Indias, donde portugueses y españoles trasladaron sus hábitos de producción y consumo. 
Apreciación de la fruta en obras literarias (I): entre poemas épicos y viajeros (siglos VIII - XVI) / Pablo Lacoste, Amalia Castro

Algunas regiones donde los nichos ecológicos eran adecuados, lograron importantes avances en el campo de la fruticultura.

Este artículo indaga sobre este proceso, y procura examinar la reconstrucción de la cultura de apreciación de la fruta en Europa, desde el Medioevo hasta el Renacimiento. Las percepciones sobre el cambio de actitud con respecto al paisaje y sus componentes se apoyan en las tesis desarrolladas por Corbin (1988), quien plantea un análisis que parte de las manifestaciones artísticas y literarias para comprender procesos culturales complejos. Inspirados en Corbin, los autores de este trabajo se han interesado en reconstruir el itinerario de la cultura de la apreciación de la fruta, a partir de obras literarias. En esta primera entrega, se examinan los poemas épicos medievales, el libro sagrado de los musulmanes y relatos de viajeros, abarcando un periodo que se extiende entre los siglos VIII y XVI.

Esta primera parte, por tanto, nuclea, el análisis de la fruta en la temprana Edad Media europea, examinando nueve obras de la literatura épica medieval, relatos como Beowulf (siglo VIII), Cantar de los siete infantes de Lara (escrito alrededor del año 1000), Canción de Roldán (fines del siglo XI) y el texto español que se escribió en su respuesta, los Romances de Bernardo del Carpio (Siglo XII), el Poema de Fernán González (siglo XIII), Cantar del Mio Cid (siglo XIII), Cantar de la Campana de Huesca (Siglo XIII), Cantar de Roncesvalles (Siglo XIII), Cantar de los Nibelungos (siglo XIII) y El Mago Merlin (escrito por Robert de Boron, entre 1230 y 1250). En ellos, se refleja cómo, en la primera mitad de la Edad Media, Europa perdió la cultura de la fruta y los frutales.

El segundo apartado muestra, por contraste, la valoración que hace El Corán, libro sagrado de los musulmanes, el cual operaría luego como disparador del proceso de recuperación de la cultura de los frutales en Europa y el mundo. El tercer apartado examina relatos de viajeros, particularmente Los viajes de Marco Polo por China e India (siglo XIII) y la Navegaciones y peregrinaciones en Turquía, relatos de Nicolás de Nicolay por los pueblos del Mediterráneo Oriental (1551).

\section{La fruta en la literatura épica medieval}

Dentro de la literatura épica medieval examinada, llama la atención la ausencia casi total de la fruta. Un buen ejemplo es Beowulf. Se trata de un poema heroico que dramatiza hechos históricos pertinentes al pueblo anglosajón en su migración hacia Inglaterra, incorporando elementos

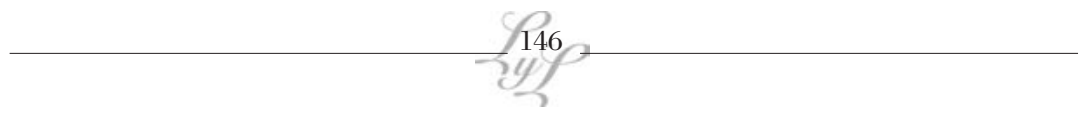


fantásticos. Beowulf, por ejemplo, pelea contra tres monstruos en el transcurso de la obra. En este relato no existen menciones explícitas a alguna fruta, aun cuando existen frecuentes menciones a festines organizados con motivo de alguna celebración en particular; dentro de estos episodios, los alimentos que predominan son el alcohol (vino e hidromiel) y la carne.

Algo parecido ocurre en El Mago Merlín. Relata la vida del singular mago y sus consejos a sus amigos, principalmente a Arturo, rey de Gran Bretaña, y los caballeros de la mesa redonda. En esta obra, se mencionan los banquetes, el consumo de vino, carne, trigo y pasteles de miel, pero los frutales están casi totalmente ausentes. Sólo hay una referencia a las nueces, y una rama de olivo en manos de un embajador llegado de Roma. Las nueces no se mencionan como alimento particularmente valorado, sino como parte de la frugal comida de un ermitaño. En un pasaje se relata la llegada de unos caballeros a una ermita. "Fueron admitidos en su interior, pero habrían cenado mal si no hubiesen llevado provisiones; el solitario sólo podía ofrecerles pan negro, nueces y agua" (Boron, parte II, IX: 162).Por su parte, la rama de olivo se menciona para destacar el origen distante de las visitas del rey británico: "Vieron aparecer en la puerta de la sala a doce hombres de muy alto aspecto, yendo de la mano de dos en dos, y cada uno llevando ramas de olivo" (Borón, parte II, XIV: 181).

La Canción de Roldán trata un evento histórico concreto. En efecto, Roldán es un personaje real, un comandante de las fuerzas de Carlomagno; y la historia se refiere a una batalla librada por este ejército en el norte de España. En este caso, se enumeran ocho frutales en total: dos manzanos y seis olivos. Es especialmente notable la mención que se observa en la estrofa 29, donde se relata cómo Ganelón, el suegro de Roldán, revela a los sarracenos un incidente en el cual Roldán compara la corona del rey de los sarracenos con una manzana, en un gesto despectivo que incita la ira de los sarracenos y propicia de esta forma la batalla presente en el poema.

Algo parecido ocurre con los Nibelungos. Este poema épico combina elementos y personajes de la mitología germana para crear un relato histórico de esta cultura. En la obra, solo se cuenta una mención explícita a una fruta, en este caso es la mora. Como en Beowulf, tampoco se puede decir que no se observan oportunidades para que la fruta tenga un grado más alto de presencia, puesto que hay repetidas menciones a banquetes y festines. Para estos casos, los alimentos que predominan son la carne, el pan y nuevamente el alcohol. De hecho, 
Apreciación de la fruta en obras literarias (I): entre poemas épicos y viajeros (siglos VIII - XVI) / Pablo Lacoste, Amalia Castro

la mención a la mora está ligada a este último elemento, pues se alude al vino de mora.

También resulta interesante examinar el caso del Cantar del Mio Cid. Ese poema está situado temporalmente en el periodo de la Reconquista, y cuenta la historia del Cid, un noble líder militar que conquista Valencia. En este caso en particular, sorprende la reducida cantidad de menciones a la fruta -solo hay una, junto al contexto en el cual aquélla es introducida. La mención aparece en la primera parte del poema, cuando el Cid entabla una conversación con un burgalés que simpatiza con su situación, poco tiempo después de haber sido desterrado. Dice el cantar: "Más tarde o más temprano, el rey me considerará buen amigo. Si no, cuanto dijo no me importa un higo". Esta única referencia sorprende a la luz del extensivo contacto que la cultura española tuvo con el mundo árabe, y que además se puede ver plasmado en el mismo poema. Si bien el Cid libra batallas con moros en territorio español, un elemento crucial de la obra es la amistad que el Cid mantiene con un jefe moro. De esa forma, se podría esperar que hubiese más menciones; pero, sin embargo, se sigue una tendencia similar a la observada en los casos anteriores, donde se nombran ciertos alimentos, pero la fruta no está incluida. Similares son los casos de los cantares españoles ya mencionados ${ }^{1}$, en los que no se registra ningún frutal.

Una buena excepción, por el número de menciones de fruta que aparece en el texto (no por el sentido que se le da), es el Poema de Fernán González. Escrita en época cercana al Cantar del Mio Cid (Ramón Menéndez Pidal lo fecha hacia 1255) se contextualiza, como aquel, en época de reconquista concentrando la acción del conde de Castilla (Fernán González, quien habría vivido en el siglo X) contra tres adversarios igualmente poderosos: Almanzor (moro), el rey de Navarra y el rey de León por la independencia de Castilla. La autoridad del conde permitió defender a Castilla libre y soberana, pues la liberó del lazo feudatario que la ligaba al reino de León, asegurando la continuidad del legítimo poder visigodo en esas tierras (Galindo Hervás, s/f; Menéndez Pidal, 1951; López, 2001). En este texto, se alude a castañas (2), piñones, granados, higo (2), manzanas (1) y arvejas (2). El contexto para todos los mencionados es siempre el mismo: no valer un higo equivalía a no valer una castaña y era, también, en este poema, lo mismo que Mafomat que, aún con todo su poderío, no valía "tres arvejas" (PFG, 35). La excepción

1 Cantar de los siete infantes de Lara, los Romances de Bernardo del Carpio, Cantar de la Campana de Huesca y Cantar de Roncesvalles.

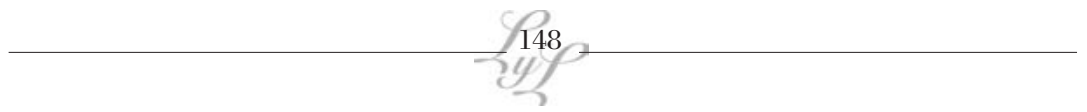


(con reparos) a esta regla es la manzana, que aparece con el personaje de Lope el vizcaíno, uno de los caudillos del ejército cristiano, que era "bien rico de manzanas, pobre de pan y vino" (PFG, 57).

La fruta, así, es utilizada en términos despreciativos, de poco valor, cuestión que es sintomática y sostenible con la figura del héroe, un ser superior sin carencias ni necesidades de ningún tipo, entre las que se incluía el comer. La sociedad europea medieval respondía a este ideal representativo y figurado por Dios, quien creó a la nobleza para ser ejemplo de veracidad, valentía, moralidad y dulzura (Huizinga, 1965). Los cantares reflejan los mismos conceptos en el héroe, quien ya no disfrutaba de los placeres mundanos o del pueblo común, y por tanto no carecía de nada y prescindía incluso de lo más fundamental como la comida. Esta exaltación del héroe aristocrático justificaba la posición que ocupaba el grupo hegemónico en la distribución del poder económico, político y social, a la vez que garantizaba la reproducción de ese mismo orden (Chamorro, 2008).

En este sentido, la novela picaresca refleja, desde los estratos bajos de la sociedad, el hambre, la comida y la bebida que tan preciadas fueron. Buenos ejemplos de ello son el Lazarillo de Tormes, Rinconete y Cortadillo y El Buscón. El protagonista siempre es el pícaro, un individuo marginal, buscavidas, que debe buscarse el sustento desde muy niño y está obligado, a través del ingenio, a cubrir sus necesidades más perentorias, como el sustento alimenticio. El vino, el pan y la carne aparecen con frecuencia, aunque un papel importante cupo a los dulces de los niños: las frutas. Aquí se destacan uvas, melones, manzanas, membrillos y limones (Negrín de la Peña, 2012).De este modo, el héroe representante de los más altos poderes sociales y políticos, se encuentra privado de lo que el pueblo come y disfruta.

La falta de disponibilidad de fruta en los relatos medievales no implica su ignorancia ni desvalorización. Para esta cultura, la fruta era un bien raro y escaso. Pero en los imaginarios del paisaje ideal, los árboles frutales estaban presentes. Cuando el Mago Merlín decide usar sus poderes sobrenaturales para construir un santuario de placer y gozar de la compañía de su amada, elige, precisamente, plantas frutales:

-Mi querida Viviana, este bosque parece horroroso, pero el amor sabe embellecerlo todo; hagamos de él una soledad encantadora, forcemos a la naturaleza a cambiar por completo de aspecto y que este desierto se convierta en un santuario del placer.- Al instante, el bosque desapareció para dejar sitio a una 
Apreciación de la fruta en obras literarias (I): entre poemas épicos y viajeros (siglos VIII - XVI) /

Pablo Lacoste, Amalia Castro

pradera encantadora, decorada con mil flores, y por cuya arena argentífera, serpenteaban los arroyos. De tramo en tramo, estos arroyos formaban encantadoras cascadas y hermosos estanques donde se veían nadar los peces más raros, por sus formas y sus colores. Los árboles, cargados al mismo tiempo de flores y frutos, servían de refugio a una infinidad de pájaros cuyos gorjeos deleitaban el oído, al mismo tiempo que la belleza de su plumaje asombraba los ojos; un aire puro y sereno debía animar siempre esta región, donde reinaba una primavera perpetua. (Borón, parte III, I: 197)

El texto representa el paisaje idealizado inglés en el mundo medieval; paisaje imposible de hallar en forma natural, y sólo concebido como resultado de una acción de fuerzas poderosas. Ese imaginario bucólico apuntaba al placer de los sentidos; el tacto gozaría de la moderada temperatura de la primavera eterna; el oído se halagaba con el canto de los pájaros y las rumorosas aguas de arroyos y cascadas; y la vista se estimulaba con el color vivo de flores y frutas. Esas frutas, que eran inaccesibles en los usos y costumbres de la vida cotidiana, estaban presentes en los imaginarios medievales como parte del lugar de la beatitud.

\section{Valoración de la fruta en El Corán}

Mientras Europa occidental se hundía en el conflicto, el atraso económico y las tensiones, la cultura de la fruta se desarrollaba en Medio Oriente, a partir del centro mismo del mundo árabe. La futura valoración de frutas y frutales tuvo, entre sus impulsores, a los musulmanes y su libro sagrado. Las páginas de El Corán promovieron la cultura de la valoración de los jardines y los frutales. Se empleaban estos espacios para desarrollar parábolas y enseñanzas (Corán II: 265-268; XVIII: 31-42; LXVIII: 17-34). En el entorno geográfico donde surgió el profeta Mahoma, la construcción de un jardín era muy costosa debido a la falta de agua. En el desierto, la presencia de agua es un bien escaso y, por lo tanto, muy valorado, lo mismo que el jardín, que solo podía existir, precisamente, si se lograba disponibilidad de agua; a su vez, con el agua y el jardín se podía conseguir frutos y un entorno de agrado. En el paisaje cultural del desierto, surgió una trilogía de elementos escasos y valiosos: agua, jardín y fruta. Sobre esta base se construía la representación del paraíso en la religión musulmana:

Albricias a quienes creen y hacen buenas obras, que tendrán unos jardines en que corren los ríos por debajo. Cada vez que se ali-

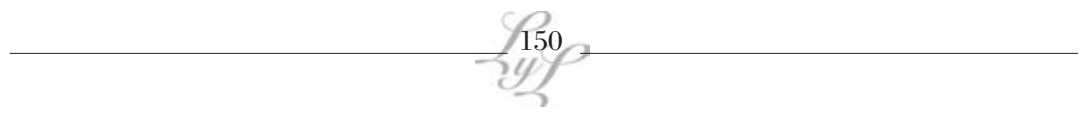


menten de esos frutos dirán: 'esto es lo que se nos dio de alimento anteriormente', pues tendrán la apariencia de los de esta vida. Tendrán esposas puras y ellos, en los jardines, serán inmortales (Corán, II: 23; III: 13; 127-130; 197; IV: 17; 60).

De acuerdo al discurso coránico, las plantas frutales eran tan apetitosas como el goce sexual. Por lo tanto, en el momento de construir el sistema de premios y castigos como herramienta de disciplinamiento social, se apeló, precisamente, a estos elementos. En efecto, las azoras dedicadas a las postrimerías, con las mejores recompensas para los justos. En el paraíso, los justos encontrarán mujeres hermosas como "rubíes y coral", recatadas y vírgenes "no tocadas por hombres ni por demonios", juntamente con "dos jardines frondosos", en los cuales hay "dos fuentes de agua corriente" además de "toda clase de frutos" (Corán, LV: 46-52). En este jardín, los bienaventurados "tendrán las frutas que escojan, la carne de pájaros que deseen; mujeres de ojos rasgados, parecidos a la perla semioculta, en la recompensa de lo que hayan hecho" (Corán, LVI: 20-23).

La valoración de los frutales y jardines, elevados a categorías sagradas a través de su incorporación al Corán, significó un fuerte impulso para la futura expansión de estas plantas, no sólo en el mundo árabe, sino también en toda su área de influencia. La fuerza de la fe tuvo fuertes efectos en la conducta de los musulmanes, porque con la misma energía con la cual se desaconsejaban algunos alimentos (cerdos, bebidas alcohólicas), se alentaban otros (frutales). En ese sentido, la presencia de los frutales en El Corán tuvo un significado crucial para la valoración de estas plantas y su futura expansión por Europa y el mundo.

Este criterio se tuvo en cuenta al construir lugares de oración, sobre todo en el sur de España, donde hallaron nichos ecológicos adecuados para el cultivo de frutales. Los árabes introdujeron su cultura en la península ibérica, y, con ella, su devoción por los jardines y los frutales. Tempranamente, Abd al-Rahmân I (m. 788), emir omeya andalusí, realizó ensayos de aclimatación de especies orientales en la Córdoba española, en suntuosos jardines repletos de plantas exóticas, que crecieron y se dispersaron rápidamente por el reino andalusí (Expiración García, 2012).

Del mismo modo, los monarcas musulmanes levantaron palacios con bellos paseos, que procuraban realizar los anhelados jardines de Iram, aquellos que el Corán mencionaba como utopía trascendental para los justos. En efecto, los suelos y climas del sur de España ofrecieron la gran oportunidad que los musulmanes habían esperado; con la diferencia que, 
Apreciación de la fruta en obras literarias (I): entre poemas épicos y viajeros (siglos VIII - XVI) / Pablo Lacoste, Amalia Castro

esta vez, esos bellos jardines con fuentes y frutales se podían plasmar en la realidad. En efecto, los árabes introducen en España el lujo oriental; el concepto del goce de vivir. En plena Edad Media, los árabes introducían en el sur de España el concepto del paisaje, la búsqueda estética, la valoración de los perfumes y la actitud para gozar la vida, proceso en el cual, se adelantaron varios siglos al Renacimiento.

A ellos se debió la construcción del palacio y sus jardines, la implantación del lujo y el refinamiento orientales en medio de la austera sociedad peninsular, la imposición de las costumbres que habrían de suplantar los hábitos más rudos de los primitivos godos. [...] A esos reyes se debe ese amor por el lujo, el placer y la belleza. Fueron precisamente los reyes quienes mandaron a construir los patios adornados con fuentes que deleitan con el rumor de las aguas, fueron ellos los que se encargaron de diseñar los jardines y los huertos perfumados con el olor de las rosas y las flores de azahar, ellos quienes idearon las estancias para el ocio y la contemplación. A los monarcas que así lo ordenaron, se debe ese amor por la vida terrenal, por el goce de los sentidos, que es una de las constantes de las leyendas moras (Restrepo, 2003: 28-29).

Por su papel en los jardines de los poderosos, los frutales en general y los cítricos en particular ganaron un lugar de privilegio en el relato. Uno de los grandes impactos que el mundo árabe ocasionó en Europa fue la introducción de nuevos cultivos como los cítricos. La gran cantidad de términos existentes para su denominación hacen pensar que fueron objeto de numerosas hibridaciones y combinaciones, lo que daría lugar a diferentes variedades. De ellos, el naranjo amargo, el limón, la lima y la azamboa fueron introducidos en España desde el siglo X en adelante (Expiración García, 2012). De este modo, los cítricos jugarían un papel importante en la conformación de los jardines andalusíes. Los mismos responden a una concepción del mundo dividido en cuatro partes, que se corresponden con los cuatro elementos: agua, aire, tierra y fuego. Su función simbólica esencial era la de ostentación de poder y riqueza (en el marco de una política de prestigio), a la vez que se procuraba obtener placer y sensualidad y desarrollar la espiritualidad. Se consideraba que lo sensorial era fundamental para lograr esos objetivos, utilizándose diferentes recursos como colores, texturas, uso del agua y aromas de las especies vegetales (Guillén, s/f). La Alhambra, en Granada, se constituyó en una magnífica muestra de la ostentación del poder soberano, de la mano de los azahares de los naranjos que se plantaron allí para el solaz regio.

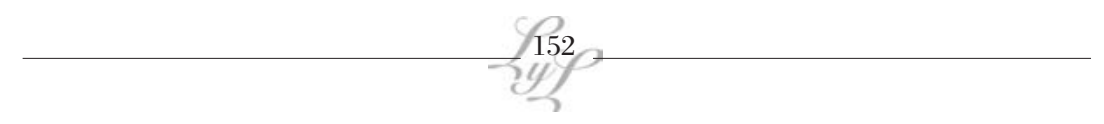


Tras la caída de Granada en manos de los Reyes Católicos (1492), los cristianos se encontraron con los deliciosos jardines moros y los aprovecharon. El palacio de la Alhambra fue residencia de los reyes españoles, pero tiempo después fue abandonado y olvidado. A comienzos del siglo XVIII, el palacio de la Alhambra volvió al centro de la escena. Para recibir al rey Felipe V, "se restauraron el palacio y los jardines". Sin embargo, poco después, el rey se retiró de allí, y nuevamente comenzó la decadencia. "La retirada de la corte fue un golpe fatal para la Alhambra: se marchitaron sus bellos jardines y las fuentes dejaron de correr" (Irving, 1832: 10). Durante un siglo, reinó el abandono y la decadencia. Recién volvería a despertar interés de las autoridades durante las invasiones napoleónicas de comienzos del siglo XIX:

cuando Granada cayó en manos de los franceses, sus tropas se acantonaron en La Alhambra, y el comandante francés vivió ocasionalmente en el palacio. Aquel monumento de grandeza y elegancia morisca se salvó de la ruina y la desolación. Se repararon los techos, se protegieron de las inclemencias del tiempo los salones y las galerías, se cultivaron los jardines, se restauraron las corrientes del agua, y las fuentes volvieron a lanzar hacia el cielo sus rutilantes chorros. (Irving, 1832: 11)

Más allá de las peripecias de los palacios y jardines, lo importante es señalar la continuidad que tuvo el aporte árabe, en el sentido de la valoración del cultivo de los frutales en el sur de España. En la década de 1820, durante la visita de un noble ruso y un intelectual norteamericano a la región, uno de los paisajes que más les llamó la atención fue, precisamente, "la imponente cadena de montañas, los fértiles valles sembrados de fragantes naranjales y limoneros" (Restrepo, 2003: 25). El segundo de esos visitantes era el escritor Washington Irving, el cual se apoyó en esos paisajes y en las ruinas de los palacios para elaborar sus Cuentos de la Alhambra (1832) en los cuales se representa, con notable detalle, la realización, en el sur de España, del jardín del Iram prometido en El Corán.

\section{Frutas y frutales en relatos de viajeros: de Marco Polo a Nicolay}

Además de conocer la valoración de la fruta por influencia directa de los musulmanes, los europeos tuvieron también la oportunidad de descubrir este nuevo mundo a partir de sus propios viajes y experiencias. Ello se 
Apreciación de la fruta en obras literarias (I): entre poemas épicos y viajeros (siglos VIII - XVI) / Pablo Lacoste, Amalia Castro

reflejó en dos importantes relatos de viajeros: el de Marco Polo (siglo XIII) y el de Nicolás de Nicolay (siglo XVI). Ambos tuvieron oportunidad de desplazarse desde Europa occidental hacia el este y hacia el sur, para recorrer territorios de los cuales había escasas noticias hasta entonces y sus detalladas observaciones se caracterizaron, precisamente, por incluir a los frutales.

Los viajes de Marco Polo fueron una buena oportunidad para que ojos europeos recorrieran, observaran e identificaran las plantas frutales que se cultivaban entonces en otras regiones. En particular, el cercano oriente, China e India. El veneciano Marco Polo (1254-1324) tuvo oportunidad de acompañar a su padre y a su tío en un viaje que se extendió por 27 años, al cabo de los cuales elaboró su enjundiosa obra. La mirada del autor estaba particularmente sensibilizada para detectar todos los elementos que pudieran significar riqueza, incluyendo minerales (piedras preciosas, metales), animales (peces, aves, mamíferos) y vegetales (cereales, plantas frutales). El autor estaba atento también a los usos que se daban a esos productos, tanto para alimentación como para vestimenta y otras utilidades.

Dada la extensión de los viajes de Marco Polo, conviene distinguir tres grandes regiones geográficas, pues cada una de ellas tiene sus características. La primera zona se extiende desde Armenia hasta Cachemira; la segunda comprende partes de China, y la tercera se dedica a la India. Naturalmente, la primera zona es la más cercana culturalmente a la región de Medio Oriente, lo cual se refleja también en las plantas frutales que allí se cultivan. Luego comienza una transición, tras penetrar en China, con algunas localidades parecidas, pero con diferencias que se van marcando a medida que se alejan del punto de partida. Finalmente, en la India, aparecen otros elementos.

Dentro de la primera zona, en Armenia Menor, el libro Los Viajes de Marco Polo menciona la presencia de vino tinto y blanco (53). Más adelante, destaca la presencia de frutas con denominación de origen: "uvas de Persia" (80). Señala que los pueblos de la zona son musulmanes, lo cual les obstaculizaba el consumo de vino. No obstante, para resolver el problema, "el vino hierve en fuego" (80), y, de esa manera, quedan autorizados a degustar de esta bebida. Esta práctica la detectó también mucho más al nordeste, en Taicán (103).

Cerca del Golfo Pérsico, en la ciudad de Camadí, encontró uno de los principales polos frutales de su viaje: "La región en que está enclavada se llama Reobar, y son sus frutos dátiles, limones, manzanas del paraíso

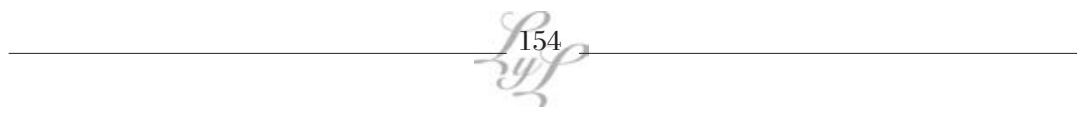


[bananas o plátanos], pistachos y otros muchos frutos que no se dan en nuestros países más fríos" (84). Un panorama parecido se presentaba en Taicán: "algunas de estas montañas son también ricas en almendras y pistachos, con los que hacen su comercio" (103). En Badascian, se menciona la presencia de aceite de nuez, dado que no tenían aceite de oliva (106), aunque lo usual era el uso de aceite de sésamo. Más recurrente es la mención de los dátiles, señalados en cinco oportunidades $(63,87-88,91)$, aunque se aclara que los bosques de Boudac producen "los mejores dátiles del mundo" (63).

En la región de Sapurgán (Shebergán) encontró "los mejores melones del mundo" que "se cultivan en grandes cantidades". Constató que los vecinos desarrollaban técnicas de conservación de estas frutas por medio de deshidratación, lo cual les permitía disponer de un producto de exportación: "haciéndolos secar, los almacenan durante todo el año de la siguiente forma: los cortan en tiras finas como correas, o bien se hace con las calabazas, poniéndolas luego al sol para desecarlas; allí se vuelven más dulces que la miel. Luego comercian con ellas, vendiéndolas en gran cantidad, una vez secas, por todos los países vecinos; todo el mundo las toma muy gustoso como alimento, pues son dulces como la miel" (101).

Después de atravesar Cachemira, el viajero deja atrás la primera zona e ingresa en la segunda, es decir, China. El autor observó las plantas frutales familiares para él, con atención a las similitudes y diferencias entre Europa y China. En ese sentido, Marco Polo estuvo atento tanto a los cultivos como a los mercados y al aprovechamiento de las plantas, incluso en productos insólitos para él.

Especial atención dedicó Marco Polo a la vid. El autor detectó la ausencia de viñas y vinos en la mayor parte de las poblaciones chinas. En el texto se reitera la idea de que "carecen de vino de uva" (154, 296, 299) y se explica que la costumbre local era consumir licor de arroz $(241,335)$. De todos modos, el vino era apreciado y consumido en la corte del Gran Khan (206-207).

Las viñas se cultivaban en dos zonas principales de China: el tramo de Cascar a Cotán en el noroeste, y el arco de Giorgiú hasta Tainfú en el nordeste. Los vecinos del reino de Cascar, musulmanes sometidos a Gengis Khan, "tienen hermosos jardines y viñas y muy buenos huertos con árboles frutales" (114). Más adelante, en Cotán "abunda todo tipo de productos pues crecen allí el algodón, el lino, el cáñamo, el aceite, los granos, el vino y todo lo demás que se da en nuestros países" (117). En cierta forma, esta semejanza se comprende por la cercanía de estos 
Apreciación de la fruta en obras literarias (I): entre poemas épicos y viajeros (siglos VIII - XVI) / Pablo Lacoste, Amalia Castro

territorios con el Cercano Oriente. Pero, a medida que se alejaba de allí, Marco Polo hallaba menor presencia de las plantas habituales del Mediterráneo.

Las viñas reaparecieron lejos de allí, en el nordeste chino, al sur de Manchuria. En la gran ciudad de Giorgiú detectó "buenas viñas" (252), igual que en el camino de allí hasta Tainfú (253). Aquí se hallaba el principal polo vitivinícola chino, según el autor: "hay en esta región muchas viñas que producen vino en abundancia; siendo ésta la única comarca en la que se hace vino de toda la provincia de Catai; y desde aquí lo llevan a las demás ciudades" (254).

Por otra parte, la presencia de la fruta en los mercados chinos fue objeto de la atención del viajero. Su interés lo movió a observar qué frutas se comercializaban, y cuáles de ellas se traían de otros lugares. En el mercado de Quinsai (Hangzou) destacó la presencia de peras, duraznos, pasas de uva y vino:

En estos mercados hay también toda suerte de legumbres y de frutos, especialmente, enormes peras muy blancas interiormente, de color cremoso y muy olorosas, llegando a pesar hasta diez libras cada pieza; hay también muchos melocotones cuando es la estación, blancos y amarillos, de sabor muy delicado. No hay uvas de viña ni de parra en todo el país; mas traen de otras regiones muy buenas pasas e incluso vino, aunque los habitantes no lo estiman mucho por estar acostumbrados a tomar el licor de especias y de arroz (335).

El durazno también era una fruta difundida en la zona; estaba presente en los mercados y se cultivaba localmente. En Cianglú (Changzou) el autor afirma que "producen unos melocotones de exquisito perfume, cada uno de los cuales pesa más de dos libras" (304).

Un aporte significativo de los pueblos orientales a la arboricultura fue la organización de uno de los primeros jardines botánicos, con especias traídas desde lugares lejanos para enriquecer la colección. La iniciativa fue puesta en práctica por el Gran Kahn, que tenía poder para ello, y algún interés en las plantas. El relato es interesante: "El Gran Señor, cuando tiene noticia que en algún lugar hay un árbol muy bello, lo hace arrancar con todas sus raíces; y con mucha tierra alrededor de aquéllas, lo hace transportar por elefantes, para plantarlo en su colina. Sea cual sea el tamaño del árbol, el Gran Khan logra siempre su objetivo. Tiene allí de este modo, los más hermosos árboles del mundo, siempre verdes y frescos" (195).

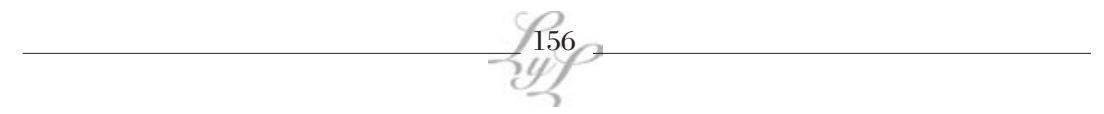


El relato no discrimina sobre las variedades de plantas que se reunieron en el Palacio del Khan. Pero, seguramente, este relato, una vez difundido en Europa, tendría fuerza para inspirar la acción de algunas autoridades locales, sobre todo cuando lograron reunir el poder suficiente para ello. Los jardines de Vaux Le Vicompte y Versalles serían buenos continuadores de esta obra.

Posteriormente, el viajero salió de China y se internó en la India. En estos extensos territorios, una de las plantas frutales más relevantes que encontró fueron los nogales del faraón o nogales de la India y sus frutos, a los cuales denominó "nueces de la India", conocidos en Occidente como "cocos". Las lianas de estas plantas se usaban para fabricar cuerdas, uno de los objetos que Marco Polo encontró en la primera zona de su viaje (89). En los territorios indios encontró gran cantidad de estas plantas y sus frutos. En el recorrido por la India se mencionan seis veces los cocos, y le siguen en importancia los dátiles (tres referencias) y las bananas o plátanos. En tanto, los cítricos aparecen en forma escasa, en el relato de Marco Polo. Solo se mencionan en dos oportunidades: una vez en las cercanías del Golfo Pérsico, y la segunda en la India. Allí detectó la costumbre de sazonar alimentos con jugo de limón: "Los habitantes de aquella ciudad, así como todos los de la India, tienen la siguiente costumbre: por hábito y también por su gusto llevan siempre en la boca cierta hoja llamada tambur, ${ }^{2}$ y continuamente las mastican y van escupiendo la saliva que se forma. Estas hojas están sazonadas con alcanfor y otras especias de gusto muy dulce a las que, además, les añaden algo de limón. Dicen que esto les mantiene con buena salud" (443).

El relato de Marco Polo permitió detectar algunas características de la producción, uso y consumo de los frutales y las frutas en Oriente durante la segunda mitad de la edad media. A su vez, dentro de este viaje, el viajero identificó tres zonas claramente diferenciadas. En la primera zona (de Armenia a Cachemira) notó la presencia de viñas y vino como tema recurrente en el relato. También se destacaba por producir los mejores dátiles y melones del mundo. Además, había referencia a pistachos, almendras, nueces, manzanas y limones, pero claramente en menor jerarquía. La segunda zona del viaje, China, mostraba un panorama intermedio con respecto a los cultivos mediterráneos. En algunas regiones, se cultivaban viñas con las cuales se elaboraban vinos y pasas. También se detectaron duraznos y peras. Pero las plantas más relevantes

2 Hoja de betel, con sabor a menta. 
Apreciación de la fruta en obras literarias (I): entre poemas épicos y viajeros (siglos VIII - XVI) / Pablo Lacoste, Amalia Castro

eran las moreras, usadas para alimentar gusanos de seda, materia prima para una floreciente industria textil regional $(227,254,261)$ y para fabricar el papel moneda que circulaba a lo largo de los dominios del Khan (227-228). Finalmente, en la India desaparecían totalmente las viñas, lo mismo que los carozos (duraznos); había dátiles, cocoteros y sus cocos, que por su identidad con la región, se denominan, precisamente, nogales de la India. El autor volvió a mencionar los cítricos, particularmente al uso del jugo de limón para condimentar alimentos.

Junto con las variedades específicas, es interesante resaltar algunos elementos relevantes. Por un lado, la cultura de la conservación de las frutas, que se destaca tanto en el caso de los melones, que se deshidrataban para poder consumirse durante todo el año, e incluso, para exportarse. También se nota la fuerza de las bebidas alcohólicas como constructoras de una identidad gastronómico-cultural. Así como Marco Polo estaba acostumbrado al consumo de vino en Europa, en Oriente detectó un proceso similar pero con licor de arroz o de dátiles. A ello se puede añadir la notable práctica, observada en el palacio del Gran Khan, en el sentido de reunir plantas y árboles para constituir un espacio social de agrado. La búsqueda de la belleza, y los valores simbólicos del prestigio que ello implicaba, movilizó al gobernante a identificar ejemplares, trasplantarlos y cuidarlos en su palacio.

La experiencia de Marco Polo inspiró a otros viajeros y exploradores a relatar sus propias peripecias. Los viajes de Nicolás de Nicolay (1517-1583) por los dominios del imperio turco, incluyendo el norte de África, las islas del Mediterráneo Oriental y zonas de Grecia y Constantinopla, fueron un emprendimiento bastante original para la época, signada por la rivalidad de la Europa cristiana con los turcos. El imperio otomano dominaba un amplio territorio, que abarcaba también Siria y el norte de África, incluyendo Egipto y Trípoli; su poder se hallaba en apogeo entonces. Había fronteras militares e ideológicas entre turcos y cristianos, motivo por el cual los contactos políticos y diplomáticos eran pobres: los problemas, por lo general, se resolvían con la fuerza de las armas. Entre los reinos cristianos prevalecía la percepción de los turcos como su principal enemigo, con los cuales se mantenía una tensión constante, en el marco de una suerte de larga guerra fría, que periódicamente se convertía en caliente, como en el sitio de Viena (1529), las batallas de Mohacs (1526) y Lepanto (1571) en Europa y los conflictos con los portugueses en la India. En este contexto, el acercamiento de un cristiano al espacio turco representaba una deslealtad a Europa, una escandalosa herejía. Se requerían motivos muy

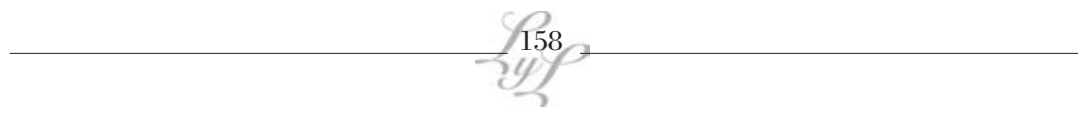


poderosos para atravesar el muro cultural que separaba ambos mundos y Nicolás de Nicolay los tenía.

En el marco de las tendencias hegemónicas de la casa de Habsburgo, a partir de sus dominios en España, Alemania y partes de Italia (Milán, Génova, Nápoles), Francia se sentía acorralada y amenazada. En este escenario y en el marco de lo que luego se llamaría una estrategia realista de política exterior, los monarcas Francisco I y Enrique II, sentían la necesidad de aliarse con una tercera potencia, con vistas a lograr un equilibrio de poder en Europa, que permitiera la subsistencia del Estado francés; y el único candidato adecuado era, justamente, el imperio otomano. Este fue el sentido de la embajada confiada a Gabriel d'Aramon en 1551, el cual fue acompañado por el militar, espía y geógrafo del rey, Nicolás de Nicolay. Éste se compenetró profundamente del significado de esta misión, y procuró llevarla adelante desde esta perspectiva, es decir, con actitud de descubridor-observador, encargado de examinar atentamente los paisajes culturales de los territorios dominados por los turcos y así construir, sobre esas nuevas bases, los acuerdos diplomáticos que tan desesperadamente requería su soberano.

Sobre la base de esta experiencia, el autor redactó sus Quatre premieres livres des Navigation et Pérégrinations, publicados bastantes años después (Lyon, 1567). En este trabajo, el autor omite información de asuntos diplomáticos y políticos, pues mantiene el secreto profesional, pero entrega un amplio informe de costumbres, cultura material, recursos naturales (incluyendo plantas frutales) y la forma de consumo (comidas y bebidas). En su redacción, tuvo en cuenta no sólo su propia experiencia sino también otros escritos, tanto contemporáneos como de la antigüedad. "En esta organización del discurso, se refleja el paisaje mental del viajero del renacimiento" (Gómez-Géraud y Yérasimos, 1989: 31). La obra despertó gran interés en su época y en tiempos posteriores. Antes de terminar el siglo XVI, fue traducida al alemán, italiano, inglés y flamenco, y reeditada varias veces; sus páginas inspiraron a otros viajeros y sus escritos. Generó numerosos comentarios y estudios. Para el presente trabajo, se ha consultado una edición reciente, acompañada de un valioso aparato crítico, titulada Dans l'Empire de Soliman le Magnifique (1989).

El Primer libro de las Navegaciones comienza con el viaje organizado para visitar al rey de Argel para lograr su alianza militar. En los primeros instantes del contacto diplomático, las frutas se hicieron presentes como medio para representar el homenaje y los honores que el monarca local deseaba expresar a su aliado. El embajador francés fue agasajado con 
Apreciación de la fruta en obras literarias (I): entre poemas épicos y viajeros (siglos VIII - XVI) / Pablo Lacoste, Amalia Castro

"toda suerte de frutas como peras, manzanas, higos, uvas y melones de excelente bondad" (61). Más adelante, un esclavo le trajo "una bandeja llena de higos y uvas, que dijo quería entregar al patrón de nuestra galera" (62). Al describir la ciudad de Argel, el autor destacó la vitalidad del mercado de las frutas, concurrido por vecinos llegados de valles, montañas y llanuras vecinas (65). También se destacaban los jardines y viñedos. "En las afueras de la ciudad, del costado oeste, se encuentran muchos bellos y deliciosos jardines poblados y decorados con diversos árboles que producen frutos de todas clases. Entre otras cosas hay melones de bondad y suavidad incomparables. Ellos tienen otra fruta llamada pastèque (sandía) -y que los italianos llaman anguries- parecidas en grosor y color a nuestras calabazas verdes de invierno. Junto a sus jardines, y a fuerza de pozos llenos de buena agua, tanto en montañas como en valles, el suelo es fértil en frutos y viñas" (66).

Estos paisajes de valles fértiles con viñas, jardines, árboles frutales y melones se repetían en otras ciudades del espacio turco, como Teddele (70). Algo parecido encontró en Hipona, la legendaria ciudad de San Agustín, donde detectó "bellos jardines abundantes en dátiles, azufaifas, higos y melones dulces" (72). Por su parte, en la isla de Pantalarée, los viajeros franceses recibieron como obsequio "una buena cantidad de uvas y de higos que llevaba en una piel de cabra sobre su espalda" (73). Más adelante, al describir la isla, destacó la producción de algodón, alcaparras, higos, melones, buenas uvas y pistacho (73-74). Un detalle pintoresco surgió después, en una escena de venta ambulante marina: "Los hombres y las mujeres son allí naturalmente buenos nadadores; nosotros tuvimos la experiencia de una aldeana que, llevando una bandeja llena de fruta, se lanzó en el mar y, a nado, la llevó hasta nuestra galera para venderla" (74).

Posteriormente, el autor recorrió la estratégica isla de Malta, en el corazón del Mediterráneo. Allí observó limoneros, naranjos y melones, pero no viñas ni vino; de todos modos, sí se podía consumir vinos que llegaban allí transportados desde Sicilia. También había abundantes "manzanas del paraíso" [bananas], dátiles, manzanas, peras, ciruelas, duraznos, higos comunes, higos de la India (77). Tras zarpar y encontrarse con otro barco, recibieron nuevos regalos frutales: limones y naranjas (99).

En el Segundo libro, se relata la visita a la isla de Chíos. Fueron recibidos oficialmente con regalos que incluían comidas deliciosas, entre las cuales se destacaban las frutas: "Enviaron un esquife cargado con diversos presentes, a saber: (...) muchas canastas llenas de limones, cidras, naranjas, granadas, manzanas, peras, ciruelas y uvas de tal grosor

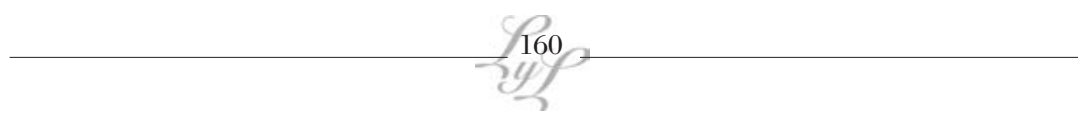


que había algunas que pesaban seis o siete libras" (104). Después de desembarcar y acomodarse en la ciudad, los viajeros recorrieron el territorio y volvieron a detectar, como en las anteriores regiones habitadas por los súbditos del sultán turco, jardines con árboles frutales. "Fuera de las murallas se encuentran los más bellos suburbios llenos de jardines, agradables y deliciosos llenos de diversas frutas de admirable suavidad y dulzor, como naranjas, cidras, limones, higos, peras, manzanas, ciruelas, damascos, dátiles y aceitunas, juntamente con toda suerte de hierbas, flores olorosas y buenas y salubres aguas de pozos y de fuentes" (108).

El concepto de denominación de origen, como atributo que destaca la calidad de un producto, se encuentra presente también en este relato. Tal como ya se había registrado en los textos bíblicos, en la gastronomía antigua de Grecia y Roma, y en los Viajes de Marco Polo, en el texto del embajador francés se entregan precisiones sobre el tema. El autor destacó un lugar en el cual "crecen los mejores y más excelentes vinos de toda Grecia, de los cuales, los antiguos, en sus banquetes y festines hacían gran estima, como recita Plinio, diciendo que César, dictador romano, distribuía, en el festín de su triunfo, cien ánforas de vino de Falerno y cien cascos de vino de Chíos, entre los comensales. Asimismo, que en su triunfo en España, él invitó con vino de Chío y Falerno" (106).

Dentro de esta isla, le llamó la atención la convivencia de dos variedades de higueras que se necesitaban mutuamente para dar frutos maduros y sazonados. El viajero comentó, con asombro, "la diversa naturaleza de dos higueras que me fueron mostradas en el jardín de los franciscanos; la fruta de una, que es buena para comer, no puede jamás madurar si no es con los higos de la otra, los cuales no son comestibles. En el tiempo de maduración, los fruticultores arrancan algunas ramas de la higuera cuyos frutos no valen nada y los colocan sobre la otra, o bien, los atan por la cola de una cantidad de los higos que no valen nada, después de haberlos picado. De esas picaduras se engendran y salen gusanitos voladores que con sus dardos y aguijones van a picar los otros higos $y$, una vez picados, logran madurar. Me han asegurado que se cultiva gran cantidad de estas higueras en la isla" (113). Además de indicar la abundancia de plantas frutales y frutas, el autor se detuvo a observar la forma de consumo.

En el Tercer Libro, se entregan datos sobre la vida cotidiana y la cultura material en la corte del sultán turco, de las gentes de Constantinopla y del pueblo turco en general. Entre otros detalles, se informa del uso de frutas en la gastronomía. Se destaca, por ejemplo, el empleo de almendras y manteca para preparar el arroz. También llama la atención 
Apreciación de la fruta en obras literarias (I): entre poemas épicos y viajeros (siglos VIII - XVI) / Pablo Lacoste, Amalia Castro

sobre el uso de frutas para obtener jugos, helados y sorbetes: "Tienen muchas bebidas artificiales y elaboradas de distinta forma que se venden en distintos puntos de la ciudad. Algunas se hacen con agua y cebada, a modo de tisana; otras con peras y manzanas o bien ciruelas hervidas, uvas, higos, peras, duraznos y otras frutas, y, de esta bebida que ellos llaman sorbete, acostumbran frecuentemente a beber con hielo o nieve en verano para refrescarse" (178).La disponibilidad de frutas llevó a los turcos a aprovecharlas para obtener subproductos, bebidas y comidas a partir de ellas. Y la expansión de los turcos por el Mediterráneo llevaría estos usos y costumbres a las costas del oeste de Europa, desde donde pasarían después al Sur de América.

Tras describir las costumbres de Constantinopla y los turcos, el autor se refiere a los árabes. A ellos dedica buena parte del Cuarto libro de las navegaciones. Dentro del gran espacio árabe distingue tres regiones: Arabia pedregosa, Arabia desértica y Arabia feliz. Esta última comprende las tierras fértiles que, en su momento, los hebreos consideraban "la tierra prometida". El autor no escatima adjetivos para valorar la fecundidad de esta región, en la cual las plantas frutales eran un referente simbólico: "Esta región, sobre todas las otras del mundo, es la más fecunda y abundante en cosas preciosas y aromáticas. Ella tiene trigo en abundancia, olivos y otras excelentes frutas. Está regada por diversos ríos y fuentes muy salubres. El país sur está poblado por muchos bosques" (222).

Después describe Armenia y, posteriormente, Ragusa (Dubrovnik). Allí detectó "casas edificadas con una bella e ingeniosa arquitectura, acompañadas de muchos jardines de agrado, plantados con naranjos, cidros, limoneros y otros excelentes árboles frutales de distintas clases que no fallan en ninguna estación del año. También se ven allí muchas bellas y claras fuentes, divinamente elaboradas, que hacen circular el agua por sus conductos y canales" (244). Escenas parecidas se repiten luego, en la ciudad de Adrianópolis, con "bellos vergeles, plenos de toda clase de excelentes árboles frutales y deliciosos jardines" (246). Similares imágenes surgen en la descripción de Grecia, donde destaca "excelentes árboles frutales" (258-259).

Esta obra refleja con claridad la sensibilidad de la mirada renacentista sobre la realidad. Se transmite un gran interés por la observación y por descubrir el mundo. Se nota la voluntad de detenerse en el reino natural, con la observación de animales y plantas. Los frutales ocupan un lugar central en el relato. Estas sensibilidades ya estaban presentes en Marco Polo. El autor prestó atención especial a las plantas, sobre todo los cítricos. Advirtió el valor simbólico que los turcos le brindaban,

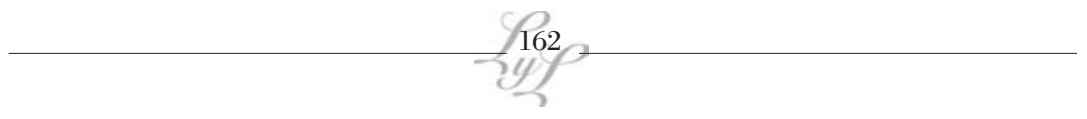


dado el lugar que ocupaban en el protocolo diplomático. En efecto, cuando se procuraba agradar, cautivar y seducir a las visitas extranjeras, con vistas a lograr algún objetivo de alianza militar o política, entre los regalos que se seleccionaban para seducir al visitante y construir poder, se utilizaron, precisamente, las frutas. Junto con su valor político, éstas ocupaban un papel en el espacio comercial: estaban presentes en el mercado, y movilizaron peculiares formas de comercialización, como los fruteros nadadores, que se arrimaban a las galeras nadando y llevando sus bandejas de frutales.

Los paisajes frutales ocupan también un papel relevante en el texto. El autor destaca los jardines, como espacios de agrado, cultivados por pueblos sensibles a los valores estéticos; y, dentro de ese ámbito, se sitúan las plantas frutales. La pareja conceptual jardín-frutal resulta una propuesta apta para impresionar la sensibilidad renacentista del autor.

La valoración de la fruta, además de sus dimensiones políticas y estéticas, surge en función del placer a través de la gastronomía. El autor observó el empleo de frutas para sazonar comidas, como las almendras que se empleaban para condimentar el arroz. También le llamó la atención el uso de la fruta para elaborar jugos y sorbetes, particularmente los helados que se obtenían de integrar jugos de frutas con hielo o nieve, refrigerio muy seductor en días cálidos. En resumidas cuentas, el viajero francés, dentro de los elementos rescatables de su viaje por el entonces extenso imperio otomano, puso énfasis en las frutas y los frutales, cuyo valor se representaba en términos políticos, estéticos y alimentarios. Representaban bienes de alta valoración, tanto por su belleza como por su sabor y frescura, a la vez que estaban rodeados de un singular poder simbólico, motivo por el cual, dentro de esa sociedad, eran muy apreciados, cuidados y valorados.

\section{Conclusiones}

La observación de las obras literarias ha permitido reconstruir el itinerario de la cultura de la fruta y los frutales en el tránsito del medioevo al Renacimiento. En una primera etapa, durante los tempranos siglos medievales, la fruta estaba en la periferia de la cultura, la política y la economía europeas. Ello se reflejó en los relatos épicos y fundacionales de los futuros estados nacionales. En la literatura épica, la fruta era apenas valorada. Las referencias eran escasas y, en la mayoría de los casos, peyorativas. Se usaba la expresión "me importa un higo" para representar una valoración negativa de un objeto. El pobre papel de la fruta en estos 
Apreciación de la fruta en obras literarias (I): entre poemas épicos y viajeros (siglos VIII - XVI) / Pablo Lacoste, Amalia Castro

relatos parece consistente con el retroceso de la fruticultura, causado a partir del derrumbe del imperio romano, la interrupción de los circuitos comerciales y la ausencia de seguridad para realizar inversiones y proyectos productivos y comerciales de largo plazo.

Cuestión parecida es posible observar con respecto al consumo de la fruta, en donde era notable el contraste entre la nobleza y el pueblo llano. El héroe, arquetipo de lo más perfecto, de aquello que debía ser imitado, no comía. El pícaro, en cambio, gozaba y disfrutaba de la comida, en especial, de la fruta, tal como se retrataba no solo en la literatura sino también en la pintura de la época.

Mientras Europa se debatía en la traumática lucha de reconstrucción institucional, social y cultural, en Medio Oriente, el profeta Mahoma ponía en marcha una nueva religión, dentro de la cual se establecía una nueva escala de valores, colocando, en su cima, los jardines con frutales. El libro sagrado de los musulmanes, El Corán, brindó un lugar de privilegio a estas plantas; y la rápida expansión de este movimiento cultural llevaría consigo estos ideales. En ese sentido, la penetración de los musulmanes a los territorios del sur de Europa, particularmente a Sicilia y la península ibérica, significó el comienzo del proceso de recuperación de la cultura de la fruta para Europa.

Este movimiento se vio reforzado por los esfuerzos de los mismos europeos por atravesar las fronteras, ir más allá de los territorios conocidos, y explorar nuevos espacios y paisajes culturales. En este contexto, las experiencias de Marco Polo y Nicolay significaron una formidable apertura mental hacia nuevos mundos, en los cuales, los frutales ocupaban un lugar relevante. Estos viajeros recorrieron los territorios fuera del espacio europeo, observaron sus plantas y la forma de cuidarlas, valorarlas y consumirlas, y volcaron el resultado de su experiencia en sus libros de viajes. Poco a poco, la valoración de los frutales y la fruta que conservaron los pueblos orientales (árabes, turcos, chinos, indios) llegaba a Europa occidental, se difundía e incorporaba a la vida cotidiana.

\section{Referencias Bibliográficas}

Amorós, M. (2003). Producción de Agrios. Madrid, Mundi-Prensa.

Anónimo (2006). Beowulf [circa siglos VII-IX]. Bogotá / Barcelona, Grupo

Editorial Norma. Versión, ensayo y notas de Armando Roa Vial.

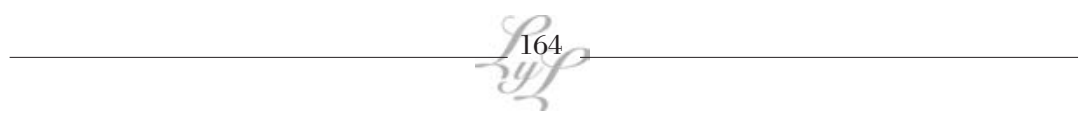


. Cantar de mío Cid [1140]. Madrid, Edad, 2007. Transcripción moderna versificada, con prólogo y notas de Luis Guarner.

. Cantar de la campana de Huesca [S. XIII] 2008. Edición digital a cargo de Justo Alarcón. Biblioteca Virtual Katharsis.

. Cantar de Roncesvalles [S. XIII] 2008. Edición digital a cargo de Justo Alarcón. Biblioteca Virtual Katharsis.

Chanson de Roland [1065]. Santiago, Editorial Nascimento, 1977. Traducción, prefacio y notas de Braulio Arenas.

. Mocedades de Rodrigo [S. XIV] 2009. Edición digital a cargo de Justo Alarcón. Biblioteca Virtual Katharsis.

. Poema de Fernán Gonzalez [S. XIII) 2009. Edición digital a cargo de Justo Alarcón. Biblioteca Virtual Katharsis.

Boron, R. de. El mago Merlín (S.XIII). Barcelona, Edicomunicación, $2^{\text {da }}$ edición, 1996. Versión española de Le roman de Merlin l'enchantateur (Paris, M. S. Boulard, 1797). Traducción española de Violeta García Santiago.

Carabaza, J. M.; García Sánchez, E.; Hernández, E.; Jiménez, A. (2004). Árboles y arbustos en Al-Andaluz. Madrid, CSIC.

Chamorro, C. (2008). "Cultura e Imagen". Cuaderno de aula Nº 5. Santiago, Ediciones UCSH.

Corbin, A. (1988). Le territoire du vide. L'Occident et le désir du rivage, 17501840. Paris, Aubier.

Defourneaux, M. (1964). La vie quotidienne en Espagne au siecle d'or. Paris, Hachette.

Fossier, R. (2007). Gente de la Edad Media. México, Taurus.

Galindo, A. "Reseña del Poema de Fernán González" Biblioteca Saavedra Fajardo de Pensamiento Político Hispánico, online.

García, E. (1995). "La gastronomía andalusí". En: VVAA El zoco. Vida económica y artes tradicionales en Al Andaluz y Marruecos. Barcelona, Lunwerg Editores. 49-57.

(2012). "Las frutas de los Califas" en Lacoste, Pablo y Yuri, José Antonio (ed.) Frutas y Frutales en Chile y el Mundo, Santiago de Chile, Universidad de Talca, inédito.

García, J. (2007). El Señorío de Oropesa. Ayuntamiento de Lagartera. 
Apreciación de la fruta en obras literarias (I): entre poemas épicos y viajeros (siglos VIII - XVI) /

Pablo Lacoste, Amalia Castro

Gomez-Géraud, M-C. et Yérasimos, S. (1989). «Introduction». Nicolay. 7-40.

Guillén, J. El jardín andalusí: almunias, vergeles y patios. Exposición virtual desarrollada por Centro Virtual Cervantes y la Fundación de Cultura Islámica. Comisario Cherif Abderrahman Jah, de la Fundación de Cultura Islámica. Comité científico: Susana Calvo, Inés Eléxpuru, Yolanda Guardione, Javier Guillén, Encarna Gutiérrez, Alfonso Jiménez, Esteban Hernández y Margarita López. Edición electrónica: Centro Virtual Cervantes (http://cvc.cervantes.es/)

Huizinga, J. (1965). El otoño de la Edad Media. Madrid, ed. Castilla S.A.

López, I. (2001). El Libro de Fernán Gonçález. Texto crítico, introducción, notas y glosario. Madrid, Biblioteca Nueva.

Mahoma. Corán. Traducción y prólogo de Juan Vernet. Barcelona, Plaza y Janés, $3^{\circ}$ edición, 1995.

McGrady, D. "Un cuento de las Mil y una noches en Boccaccio, Lope de Vega, Calderón, Corneille, Lesage y otros" Bulletin hispanique 2 (Bordeaux 2003): 465-481.

Menéndez Pidal, R., ed. (1951) Poema de Fernán González. Reliquias de la Poesía épica española. Madrid, Espasa-Calpe.

Mennell, S. (1987 [1985]). Francais et anglais a table du moyen age a nos jours. Paris, Flammarion.

Negrín de la Peña, José Antonio «La mesa del Dómine Cabra: comida y vino en la novela picaresca del siglo de oro español" En Revista de Estudios Avanzados18 (Santiago de Chile, diciembre 2012). Inédito.

Oliveira, A. H. (2010). A sociedade medieval portuguesa. Aspectos de vida quotidiana. Lisboa, A Esfera dos Libros.

Páez, F. Historia de los estilos en jardinería. Madrid, Akarl, 1982.

Pereira Millán Da Costa, A.; Goncalves, I. (2010). "O espaço urbano e o espaço rural". Matosso, José (direcçao). História da Vida Privada em Portugal. A Idade Média. Círculo de Leitores / Temas e Debates. 24-53.

Restrepo, M. C. (2003). "La Alhambra, el palacio encantado de los reyes moros". En: Irving, Cuentos de la Alhambra. 23-38.

Valdeón, J. (2004). La vida cotidiana en la Edad Media. Madrid, Dastin. (2007). Cristianos, judíos y musulmanes. Barcelona, Crítica.

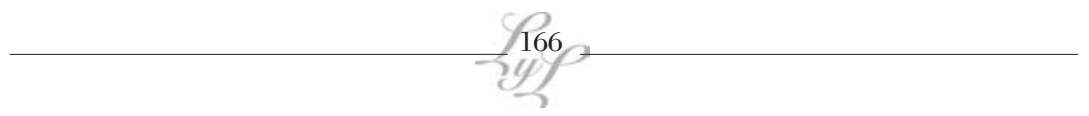

